\title{
Will They Stay or Will They Go? An Examination of the Factors Influencing User Loyalty towards News Websites
}

\author{
Benedikt Berger \\ Ludwig-Maximilians- \\ Universität München \\ benedikt.berger@bwl.lmu.de
}

\author{
Andre Geimer \\ Ludwig-Maximilians- \\ Universität München \\ andre.geimer@campus.lmu.de
}

\author{
Thomas Hess \\ Ludwig-Maximilians- \\ Universität München \\ thess@bwl.lmu.de
}

\begin{abstract}
Owing to the increased competition in electronic markets, customer loyalty has become an important success factor in e-business. However, the antecedents of customer loyalty differ between business domains. While the formation of customer loyalty in e-commerce has been studied extensively, little is known about how loyalty towards news websites develops. Integrating findings from uses and gratifications research into DeLone and McLean's theory on information systems success, we built a quality-value-satisfaction-loyalty chain for news websites. To test our research model, we conducted a survey and applied partial least squares structural equation modeling. The results reveal that loyalty towards news websites depends on both utilitarian and hedonic value perceptions, which, in turn, are influenced by content quality. Our study combines communication, information systems, as well as marketing research theories and has important implications for news website providers.
\end{abstract}

\section{Introduction}

The digitization of information dissemination and the diffusion of connected devices have disrupted traditional ways of doing business in almost every business-to-consumer (B2C) market. The availability of products and services beyond geographical boundaries and increased price transparency have enforced competition [1]. In the online environment, competitors' offers are mostly only a few clicks away [2]. The need to actively retain existing customers has therefore increased. Academic and market research have repeatedly emphasized the role of customer loyalty as a key driver of profitability for Internet businesses [3, 4]. The increasing importance of customer loyalty is also reflected by a growing body of research examining its antecedents [5, 6]. Several models have been built to explain continued product use and the formation of loyalty towards a company. However, most of this research has been conducted in the context of $\mathrm{B} 2 \mathrm{C}$ e-commerce and the findings are not necessarily applicable to other markets. Mithas et al. [7], for instance, have shown that the relative importance of website features for customer loyalty differs between business domains.

One of the markets in which the loyalty formation process has been very little investigated is that for online news. Examining the antecedents of user loyalty towards news websites is worthwhile, because online news consumption differs from online shopping in two important aspects. First, users visiting a news website have different needs than those visiting an online shop $[8,9]$. Whereas online shop users primarily wish to make a purchase, which good content may facilitate, news website users are interested in the content itself. The content quality is therefore of higher importance for user loyalty towards news websites than towards B2C e-commerce websites [7, 10]. Second, since many news websites still offer at least a part of their content for free, users usually do not need to register and disclose personal information to use these websites. Compared to online shops, this reduces switching costs and emphasizes the need to foster user loyalty towards news websites even more.

That said, only little is known about how content providers (i.e. media companies [11]) can promote loyalty towards news websites. Lin and $\mathrm{Lu}$ [12] investigated loyalty towards a news website by means of the technology acceptance model (TAM). Their results revealed direct effects of perceived usefulness and preference for a website on intention to reuse. Other studies have investigated loyalty formation towards health information websites and professional sports team websites [13, 14]. Eppler at al. [15] observed that content relevance and media quality have a positive effect on user satisfaction and subsequently on user loyalty towards content-driven websites in general. Similarly, Jaiswal et al. [10] found that, in this context, information quality has a strong influence on user loyalty. Given the limited knowledge of this topic, we strive to answer the following research question:

RQ: How does user loyalty towards news websites develop? 
In response to our research question, we built a research model based on the DeLone and McLean (D\&M) information systems (IS) success theory. Specifically, we integrated the value perceptions of news consumption from uses and gratifications (U\&G) research into the e-commerce success model by Wang [16] and Kim et al. [17] in order to adapt it to news websites. Our study is the first to combine these IS and communication science theories, which thus advances the understanding of online news recipients' behavior. Furthermore, our study offers valuable insights to content providers seeking to foster user loyalty to their websites. We proceed by introducing the D\&M IS success model and the U\&G approach before deriving and testing our research model.

\section{Theoretical foundations}

\subsection{The D\&M IS success model}

The D\&M IS success model is one of the first theories to offer an integrated view of an information system's success [18]. Based on a literature review, the authors identified six information system success dimensions. The user perceives its quality as comprising the dimensions information quality and system quality. These dimensions jointly affect the attitudinal dimension satisfaction and the behavioral dimension use, both of which also influence each other. The use of an information system and users' satisfaction with it have an impact on individuals' performance and, at least in the corporate context, on the organization's performance (impact dimensions). The first empirical evaluations supported the suggested model [19, 20]. At the same time, the model was criticized for its ambiguous use dimension and for its confounding causal and procedural dependencies [21]. In response, DeLone and McLean [22] updated their IS success model. Taking consumers' private use of IS into account, they introduced service quality as an additional dimension, redefined use as the users' interaction with the system, and summarized the impact dimensions under the term net benefits. These benefits' operationalization depends on the setting in which the model is applied.

Even before its update, researchers had transferred the D\&M IS success model to consumer applications on the Internet, stating that websites could also be perceived as IS [23, 24]. After DeLone and McLean [25] had explicitly demanded that their updated model be applied within the e-commerce context, several e-commerce success models were proposed. Whereas the quality dimensions in these models were mostly the same as in the updated D\&M IS success model, the behavioral and attitudinal dimensions comprised different constructs, such as usefulness, ease of use, or attitude towards the site [26, 27]. Reflecting customer loyalty's high importance in e-commerce, many of these studies employed loyalty intentions as the net benefit dimension [16, 28].

Despite its widespread use in e-commerce research, the D\&M IS success model has rarely been transferred to other e-business domains. To our best knowledge, no study has as yet applied the D\&M IS success model to news websites. However, some of its improvements in $\mathrm{B} 2 \mathrm{C}$ e-commerce research facilitate this transfer. The e-commerce success model by Kim et al. [17] is especially suitable for this purpose. Their model is based on that of Wang [16], who inserted perceived value as a result of the three quality dimensions in his model. He furthermore used intention to reuse as a dependent variable to achieve congruence with the quality-value-satisfaction-loyalty chain developed in marketing research [29]. Given the transaction-oriented purpose of e-commerce websites, this congruence between IS and marketing theory is highly desirable. Building on this work, Kim et al. [17] then introduced different kinds of value perceptions, namely utilitarian and hedonic shopping value. This differentiation fits the purpose of our study, since news consumption, like online shopping, has been shown to be driven by hedonic and utilitarian motives [9]. Consequently, we decided to build on their research model in our study.

\subsection{The U\&G approach}

Similar to the analysis of the motives behind buyer behavior in marketing research, communication science has investigated why people use certain media. Studies on this topic have been subsumed under the term $U \& G$ research [30]. Other than previous media consumption theories, the U\&G approach is based on the assumption that individuals are not passively exposed to mass media, but actively choose what they want to consume. Recipients are assumed to make media choices in response to their needs, which they seek to satisfy. That is, they expect particular uses or gratifications, depending on the media they use. Moreover, studies following the U\&G approach presume that individuals are sufficiently aware of their media consumption motives to report on them. Owing to the exploratory nature of many $U \& G$ studies, a large number of possible media usage motives have been suggested. Katz et al. [31] clustered these into five categories: cognitive needs, affective needs, selfaffirmation needs, social needs, and needs related to tension-release or escapism. 
While the $U \& G$ approach has its origin in research on traditional mass media use, it has also been applied to explain the use of digital media. Eighmey and McCord [32], as well as Papacharissi and Rubin [33], found that information seeking and entertainment were important motives for using the Internet. Further research has investigated the specific motives for online news consumption $[9,34,35]$. Like the studies on Internet use in general, this research uniformly considered information- as well as enjoyment-related motivations relevant predictors of use behavior. Among these predictors, surveillance, which Luo and Remus [34] define as the need to "know what is going on in the world" (p. 285), and entertainment have been repeatedly shown to have a strong influence on news consumption on the Internet $[9,35]$.

\section{Development of hypotheses}

Our research model integrates findings from B2C e-commerce success research as well as U\&G studies. Using the D\&M IS success model as our basic framework, we adopt Wang's [16] model, including the quality-value-satisfaction-loyalty chain. Following Kim et al. [17], we split the value dimension into a utilitarian and a hedonic component. Owing to our research setting, these components consist of gratifications sought when using news websites [9]. Figure 1 depicts our research model. We develop each of the hypotheses in the following sections.

\subsection{Influences of quality dimensions}

Previous research on the development of loyalty intentions agrees that these are rooted in quality perceptions [29]. In line with the updated D\&M IS success model, it has become common practice in IS research to separate website quality into the three dimensions information quality, system quality, and service quality [27]. However, depending on the type of website, the relevance of these dimensions differs. It can be assumed that most users of news websites do not usually communicate individually with the content provider. Because service quality implies customers' assessment of their interaction with the vendor [27], we omitted this quality dimension. Instead, our study emphasizes the information quality dimension, since news website users are primarily interested in the provided content [10]. To account for the content on news websites not only conveying information, but perhaps also serving other purposes, such as entertainment or education, we replaced information quality with content quality.
According to the quality-value-satisfaction-loyalty chain, users compare their quality perceptions with their perceived sacrifice, which can be either monetary or non-monetary in nature $[16,36]$. The result of this comparison is the perceived value, which can be divided into utilitarian and hedonic value [37]. Utilitarian value results from a conscious pursuit of an intended consequence, whereas hedonic value denotes the pleasure obtained from an activity. Utilitarian and hedonic value are conceptually similar to the surveillance and the entertainment gratifications obtained from media use. Surveillance describes the conscious pursuit of being knowledgeable about current issues. It is therefore a utilitarian gratification. The entertainment gratification refers to the enjoyment and, thus, the hedonic value of consuming content [35]. If a website offers superior content quality, it is reasonable to assume that the surveillance and the entertainment gratifications are higher. Consequently, we propose the following hypotheses:

Hla: Content quality has a positive influence on surveillance.

H1b: Content quality has a positive influence on entertainment.

Given that users' reason for visiting a news website is not the system itself, but the content it provides, its functionality is of less importance than that of online shops [7]. We therefore assume that the system quality does not contribute to fulfilling the gratifications the user seeks. Nevertheless, a flawlessly working website remains a fundamental prerequisite for news consumption on the Internet [12]. Low system quality would have a detrimental effect on the user experience and satisfaction with the website. We thus hypothesize:

H2: System quality has a positive influence on satisfaction.

\subsection{Influences of gratifications}

Moving on to the next step in the quality-valuesatisfaction-loyalty chain, we propose that if users achieve the gratifications they seek, their satisfaction with a news website increases. The link between value perceptions and satisfaction has been established multiple times $[16,29]$. It is reasonable to transfer this link to gratifications fulfilled by using news websites, because gratifications constitute users' expectations of media consumption [30], while the confirmation of prior expectations results in satisfaction [24]. Our next hypotheses therefore posit:

H3a: Surveillance has a positive influence on satisfaction.

H3b: Entertainment has a positive influence on satisfaction. 


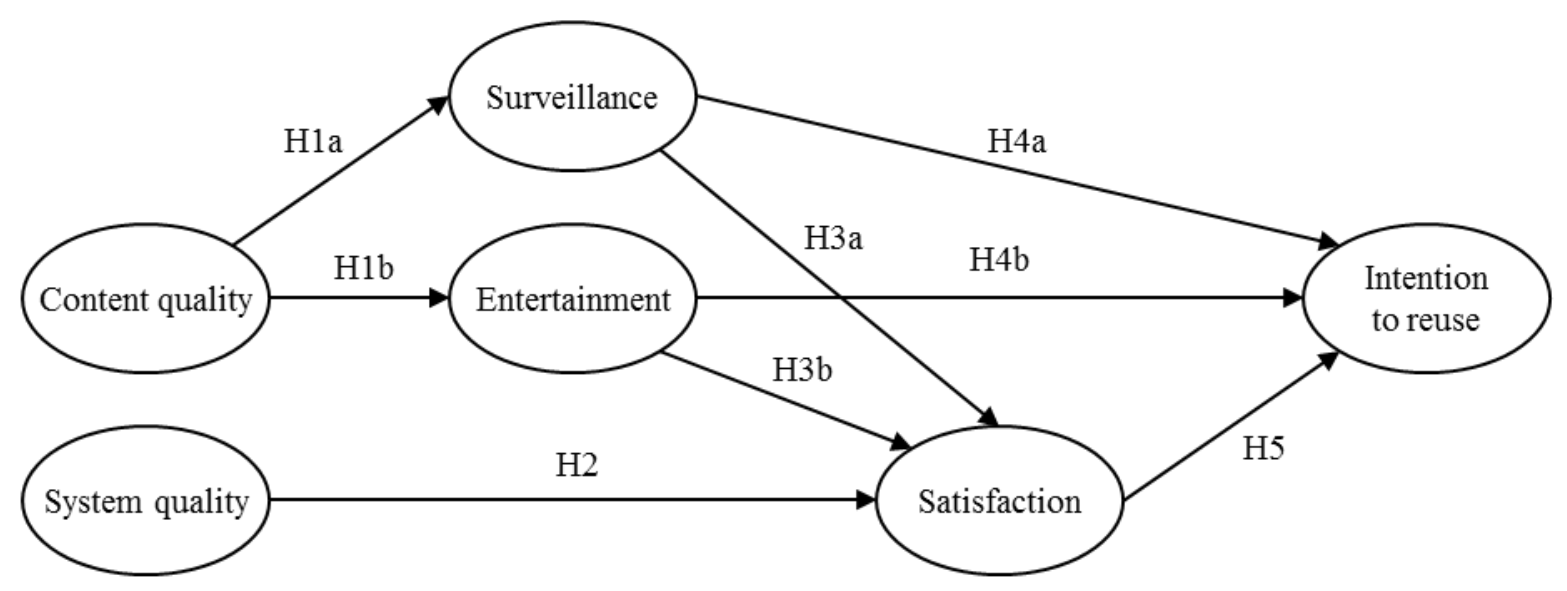

Figure 1. Research model

Furthermore, in U\&G research, many studies have found evidence of the effect of gratification achievement on user behavior $[9,34]$. If consumption of their selected media satisfies users' needs, which determine their media selection, the ongoing and future use of these media is promoted [38]. We hypothesize:

H4a: Surveillance has a positive influence on intention to reuse.

H4b: Entertainment has a positive influence on intention to reuse.

\subsection{Influence of satisfaction}

Besides fulfilling gratifications, satisfaction with a news website is presumed to influence users' intention to reuse it. Both marketing and IS research have confirmed the effect of satisfaction on intention to reuse, which is the last nexus in the quality-valuesatisfaction-loyalty chain $[6,29]$. Thus, our final hypothesis is:

H5: Satisfaction has a positive influence on intention to reuse.

\section{Method}

\subsection{Survey design}

We conducted an online survey of German students to estimate our research model and test our hypotheses. The questionnaire was developed by means of the software Unipark by QuestBack and consisted of three parts. First, the participants were shown a list of the 25 most visited German news websites as of November 2015. We had obtained traffic data from the German Audit Bureau of Circulation to draw up this list [39]. The respondents were asked which of these websites they knew and had visited at least once. Based on their answers, they subsequently received a random subsample of the websites known to them and were asked to indicate which of these they had last visited. All of the following questions concerned the news website chosen in response to this question. This selection procedure ensured that the respondents were not simply questioned about their favorite news website, which would have biased our sample towards loyal users. The second part of the survey referred to our research model's constructs, with the quality dimension constructs positioned at the beginning and the intention to reuse at the end of the questionnaire. Third, we questioned the respondents about their news consumption behavior and demographic variables.

\subsection{Measures}

We obtained previously established scales and carefully adapted them to our research setting to measure the constructs in our survey. For content quality (CONT) we relied on the content perception scale by Sundar [40], which he specifically designed for news websites. The system quality (SYST) construct was adopted from Schaupp et al. [41] and is the only formatively modelled construct in our study. We measured the gratification dimensions, surveillance (SURV) and entertainment (ENTE), by using the scales by Vincent and Basil [42], which had previously been applied to news websites [9]. The satisfaction (SATI) and intention to reuse (INTE) scales in our questionnaire stem from Bhattacherjee's [43] seminal study on IS continuance. The measurement of SATI consists of a four-item, seven-point semantic differential. The remaining constructs were rated on seven-point, Likert-type scales. All the items were separately translated into German and back into English, to avoid any change in the meaning. 


\subsection{Data collection}

Prior to the main survey, we conducted a pre-test to identify mistakes and ambiguities in the questionnaire. Following the 15 testers' comments, we slightly altered the wording of the questions. The main survey took place at the beginning of 2016. We distributed the questionnaire by using the mailing list of a large public German university and student groups on Facebook. To incentivize participation in the survey, we announced a lottery that would give five shopping vouchers worth $€ 20$ each to the winning respondents. A total of 548 persons started the questionnaire, with 351 completing it. We screened the data for unengaged responses, but did not have to exclude any case. Of the 351 respondents, $55.6 \%$ were female and the average age was 25.5 years. $97.1 \%$ of the sample held at least a high school diploma, while $77.5 \%$ were students. More than half of the participants earned less than $€ 1,000$ per month ( $10.5 \%$ chose not to indicate their income).

\section{Results}

\subsection{Measurement model analysis}

Before estimating the structural model, we conducted an exploratory factor analysis (EFA) of all the reflective measures with IBM SPSS Statistics 23, using the maximum likelihood extraction method and promax rotation. We had to exclude several CONT, SURV, and ENTE items to obtain a clear pattern matrix. The remaining items were included in a confirmatory factor analysis (CFA) with SmartPLS 3 [44] to assess the reflective measurement models.

Table 1 shows the CFA results. We used Cronbach's $\alpha$ [45] and composite reliability $\left(\rho_{c}\right)$ to evaluate the internal consistency reliability. Both exceeded the threshold value of 0.7 for all constructs, which can therefore be regarded as reliable [46]. Similarly, the indicator reliability is established, as all the standardized factor loadings were larger than 0.7 [47]. To determine the validity of our constructs, we examined the average variance extracted (AVE), cross loadings, and the latent variable correlation matrix.
Since the AVE values were above 0.5, they indicate that the variance in the indicators accounted for by their constructs is larger than the variance due to measurement error. This was true of all our constructs and convergent validity is therefore established. Further, discriminant validity is given if the square root of the AVE of each construct is larger than its correlation with all other constructs (Fornell-Larcker criterion [48]) and each item has the highest loading on the construct to which it is assigned. All of our constructs fulfilled these criteria.

Finally, we evaluated the validity of the formative SYST construct. In formative measurement models, collinearity between the items can cause difficulties with parameter estimation. We therefore calculated the variance inflation factor (VIF) of each of the three SYST indicators. Because the highest VIF value was 3.527, which is below the cut-off value of 5 [47], collinearity does not pose a problem. Next, we tested the significance of the indicators' weights by using a bias-corrected bootstrapping without sign change and 5,000 samples. The first two SYST indicators proved to be not significant $(\mathrm{p}>0.1)$. However, given their loadings of respectively 0.862 and 0.792 , both indicators were retained in the measurement model. The appendix shows the list of all the validated items.

\subsection{Structural model analysis}

We estimated our research model, using partial least squares (PLS) structural equation modeling (SEM) with SmartPLS 3 [44]. The estimation results are displayed in Figure 2. Similar to the validation of the formative SYST construct, the first step was to assess whether collinearity between our latent variables was present. The highest VIF value in the structural model was 1.387 , showing that collinearity is not an issue. That said, we next evaluated the significance of the path coefficients by applying the same bootstrapping procedure as before. All the path coefficients were significant at the $p<0.01$ level, except for the effect of ENTE on INTE, which was significant at the $\mathrm{p}<0.05$ level. The results therefore support all of the hypothesized relationships.

Table 1: Factor loadings, internal consistency criteria, AVE, and correlation matrix

\begin{tabular}{|l|c|c|c|c|c|c|c|c|c|c|}
\hline Construct & Loadings & $\boldsymbol{\alpha}$ & $\boldsymbol{\rho}_{\mathrm{c}}$ & AVE & SYST & CONT & ENTE & INTE & SATI & SURV \\
\hline CONT & $0.774-0.916$ & 0.942 & 0.952 & 0.713 & 0.439 & 0.844 & & & & \\
\hline ENTE & $0.830-0.924$ & 0.865 & 0.918 & 0.789 & 0.329 & 0.259 & 0.888 & & & \\
\hline INTE & $0.721-0.911$ & 0.790 & 0.876 & 0.704 & 0.409 & 0.569 & 0.402 & 0.839 & & \\
\hline SATI & $0.807-0.894$ & 0.877 & 0.915 & 0.703 & 0.506 & 0.618 & 0.425 & 0.658 & 0.854 & \\
\hline SURV & $0.790-0.877$ & 0.870 & 0.910 & 0.716 & 0.393 & 0.525 & 0.393 & 0.438 & 0.455 & 0.846 \\
\hline
\end{tabular}

Note: The reported factor loadings are standardized. The underlined diagonal elements in the correlation matrix are the square root of the AVE. 


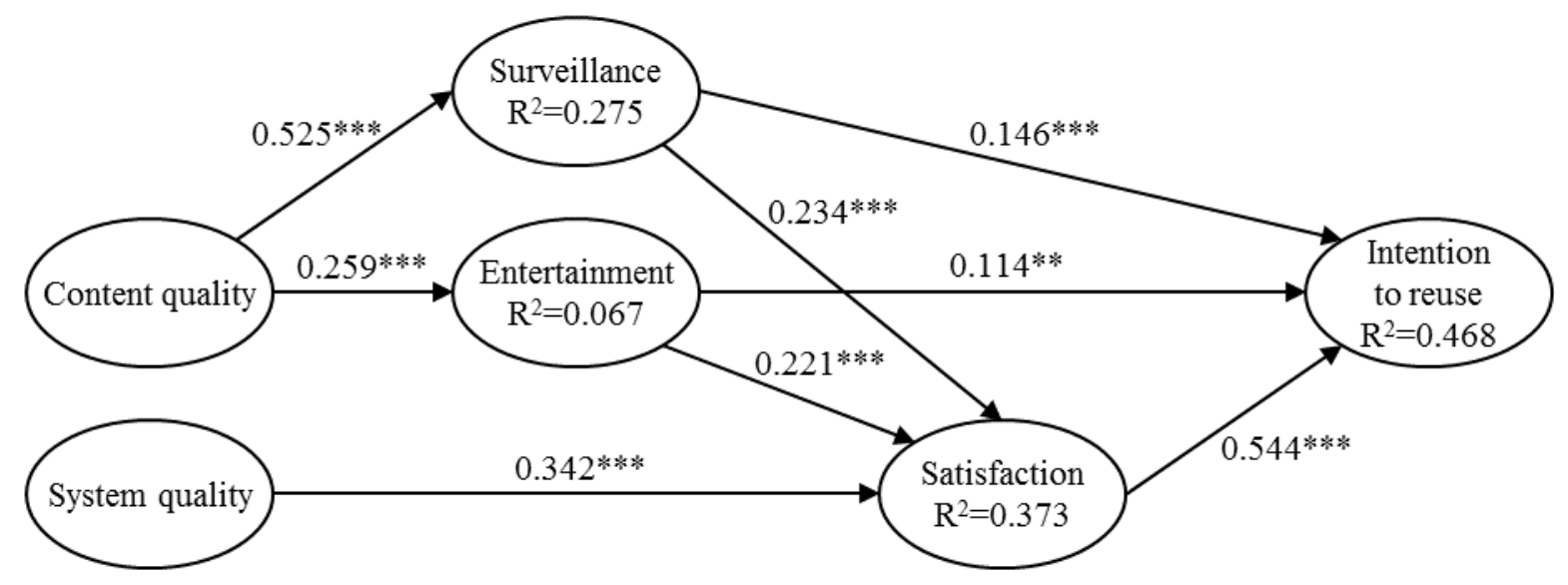

Figure 2. PLS estimation results $\left(n=351 ;{ }^{* \star *} p<0.01 ;{ }^{* *} p>0.05 ;{ }^{*} p<0.1\right)$

To control for heterogeneity within in our sample, we used multi-group analyses to determine the effects of gender, age, education, and income on our results [49]. We split our sample into two groups for each of these analyses. To build age groups, we performed a median split and separated the participants younger than $25(n=165)$ from those 25 and older $(n=186)$. Similarly, we compared non-graduates $(n=164)$ with graduates $(n=187)$, and subjects with a monthly income of less than $€ 1,000$ ( $n=200)$ with those earning $€ 1,000$ or more $(n=114)$. The results of the multi-group analyses of gender and income revealed no significant differences in the structural model. However, education and age significantly altered the effect of SURV on SATI, which was stronger among nongraduates and younger participants than among graduates and older participants. This means that achieving surveillance gratification contributes more to younger and less educated users' overall satisfaction with a news website. Nevertheless, the effect is still positive and significant within the groups of older and higher educated participants. Since only the strength of the effect, but not its direction or existence, was affected, it can be concluded that, in terms of heterogeneity, our results are robust.

Overall, our model explains more than a third of the variance in SATI $\left(\mathrm{R}^{2}=0.373\right)$ and almost half of the variance in INTE $\left(\mathrm{R}^{2}=0.468\right)$, which means that its predictive accuracy is sufficient. To determine how much explanatory power each of the exogenous constructs contributed, we also analyzed the effect sizes by means of Cohen's $f^{2}$, which is an indicator of the change in $\mathrm{R}^{2}$ when an exogenous variable is excluded from the analysis [50]. As a rule of thumb, values below 0.15 indicate weak effects, values between 0.15 and 0.35 moderate effects, and values above 0.35 strong effects. In our model, we found that
CONT has a strong effect on SURV and SATI on INTE. The effect of SYST on SATI was moderate and the remaining effects weak. The sizes of all the effects are listed in Table 2.

Table 2: Effect sizes

\begin{tabular}{|l|c|}
\hline \multicolumn{1}{|c|}{ Relationship } & $\boldsymbol{f}^{\mathbf{2}}$ \\
\hline CONT $\rightarrow$ SURV & 0.380 \\
\hline CONT $\rightarrow$ ENTE & 0.072 \\
\hline SYST $\rightarrow$ SATI & 0.151 \\
\hline SURV $\rightarrow$ SATI & 0.067 \\
\hline ENTE $\rightarrow$ SATI & 0.063 \\
\hline SURV $\rightarrow$ INTE & 0.030 \\
\hline ENTE $\rightarrow$ INTE & 0.019 \\
\hline SATI $\rightarrow$ INTE & 0.400 \\
\hline
\end{tabular}

\section{Discussion}

In this study, we set out to investigate the loyalty formation process in terms of news websites. Transferring the quality-value-satisfaction-loyalty chain from online shopping to news consumption on the Internet, we built a research model based on the U\&G approach and the D\&M theory of IS success. The model suggests that news website users obtain two kinds of gratifications, which represent the value of online news consumption. This value is hypothesized as increasing with the content quality and comprises a hedonic component - the entertainment that the content provides - and a utilitarian component - surveillance gratification. The results of our survey confirm the proposed relationships, although the content quality influences the achievement of surveillance gratification much stronger than the entertainment of the user does. In contrast, both gratifications have a similarly strong effect on the users' satisfaction with a news website. 
We found differences between the user groups regarding the utilitarian value component's effect on satisfaction. This effect was stronger among younger and less educated participants in our survey than among the higher educated and older ones. The latter apparently demand more of a news website than just being kept up to date or scrutinize the provided content more critically. Consequently, they are harder to satisfy by merely fulfilling surveillance gratification. At this point, we note that, in our sample, age and education are positively correlated and further analysis would be needed to disentangle their effects on the relationship between surveillance and satisfaction.

Additionally, the gratifications have a direct and an indirect effect on the intention to reuse a news website. The direct effect implies that users, who achieved the gratification they sought when deciding to visit a certain news website, are inclined to opt for the same website again in the future. The indirect effect operates through satisfaction, which system quality simultaneously influences comparatively strongly. Despite the system having no value to the user, but only serves as a means to provide content, system quality is highly relevant for satisfying users. Last, ensuring users' overall satisfaction is crucial, because this has a very strong influence on the intention to reuse.

\section{Conclusion}

\subsection{Implications}

Our study has important theoretical and practical implications. From a theoretical perspective, it merges findings from communication science, IS, and marketing. While previous research established the link between quality, satisfaction, and loyalty in terms of different kinds of content-driven websites, the quality perceptions in these studies focused on system-based characteristics, such as ease of use or responsiveness $[10,12-14]$. As far as we are aware, our study is the first to examine the relevance of users' content-related demands regarding the forming of loyalty towards news websites. Specifically, we showed that satisfaction with a news website and loyalty towards it are the results of the fulfillment of a priori anticipated gratifications, which constitute the reason for visiting a news website. These motives were largely neglected in previous research on news website use. Our study fills this void and demonstrates that system-related factors may not always be sufficient to explain user behavior. Instead, user behavior is an interplay between systemand content-related factors that leads to users being satisfied with and loyal towards news websites.
By transferring the D\&M IS success model from B2C e-commerce to news websites, and integrating findings from $U \& G$ research into this model, we furthermore demonstrated the generalizability of the D\&M IS success model to a new business domain. Despite motives that differ from those of online shopping triggering news consumption on the Internet, the loyalty formation process is based on the same relationships between quality-based, attitudinal, and behavioral dimensions. Our findings thus encourage the adaption of the D\&M IS success model, including the quality-value-satisfaction-loyalty chain, to other online consumer applications, while taking the respective motives for their use into account.

In addition, online news providers can draw on our findings to foster user loyalty towards their websites. Such news providers should first note that although content quality primarily influences surveillance, entertainment has an equally strong effect on user satisfaction and intention to reuse. If content providers were to make their websites more entertaining without a loss of informational relevance, they should increase user satisfaction and loyalty. A higher entertainment gratification might be provided by adding content that increases users' emotions, such as excitement or enjoyment, or by presenting existing content in more attractive ways, for example, by using interactive graphics. Whether these measures would increase profitability depends on their costs and the content monetization, neither of which was part of this research project. Second, online news providers should constantly monitor and improve their system quality. If the system quality is low, users will scarcely be satisfied, regardless of the content quality. In this regard, the website's compatibility with all kinds of browsers, devices, and operating systems; short loading times; an intuitive and clear navigation; as well advertisements' seamless integration are important measures. The high diffusion of ad-blocking software shows that annoying advertising formats still hamper users' experience of many content-driven websites. Presenting commercial messages in new ways, as for instance by native advertising, might alleviate this issue.

\subsection{Limitations and further research}

Despite our utmost care to ensure the correct execution of this study, it is subject to several limitations. First, we gathered data using a student sample. The use of news websites is mostly free, therefore an income-related bias in our results is unlikely. However, students may have different news consumption preferences and habits than Internet users in general. A replication of our study based on a 
sample representative of the whole population of Internet users would therefore be welcome. Second, our content quality measure did not explain a large amount of the variance in entertainment. It follows that either entertainment on news websites depends heavily on non-content components, or the current content quality measures focus too strongly on the informativeness of the content and neglect the entertaining aspects, which seems more likely. Hence, a redefinition of content quality that encompasses both utilitarian and hedonic content facets might further improve our understanding of users' news websites perceptions. Developing a more differentiated content quality construct might also allow for assessing which content properties lead to the achievement of specific gratifications, such as entertainment and surveillance. Third, we perceived news websites as a common type of websites sharing the same characteristics. However, further differentiations between news websites are possible. Lopes and Galletta [51], for instance, focus on websites providing intrinsically motivated online content, which is content that users consume for its own sake and not because they gain something from it. Drawing on this distinction within our research setting might reveal differences between these types of websites regarding the utilitarian and hedonic value obtained. Fourth, we focused on two specific gratifications to represent utilitarian and hedonic value. Previous research has identified other news consumption gratifications, such as escapism [9, 34]. Taking these into account might result in a richer picture of the motivations that drive user behavior and might improve the model's predictive accuracy even further. Finally, our study was conducted in Germany and is therefore influenced by German news websites' content and design. Since journalism traditions and media perceptions tend to differ between countries, further research is needed to assess the generalizability of our results to areas with different cultural backgrounds.

\section{References}

[1] Bakos, J.Y., "Reducing Buyer Search Costs: Implications for Electronic Marketplaces", Management Science, 43(12), 1997, pp. 1676-1692.

[2] Srinivasan, S.S., Anderson, R., and Ponnavolu, K., "Customer Loyalty in E-Commerce: An Exploration of Its Antecedents and Consequences", Journal of Retailing, 78(1), 2002, pp. 41-50.

[3] Watson, G.F., Beck, J.T., Henderson, C.M., and Palmatier, R.W., "Building, Measuring, and Profiting from Customer Loyalty", Journal of the Academy of Marketing Science, 43(6), 2015, pp. 790-825.
[4] Adobe Systems Incorporated, The ROI from Marketing to Existing Online Customers, Adobe Systems Incorporated, San Jose, CA, 2012.

[5] Casaló, L., Flavián, C., and Guinalíu, M., "The Role of Perceived Usability, Reputation, Satisfaction and Consumer Familiarity on the Website Loyalty Formation Process", Computers in Human Behavior, 24(2), 2008, pp. 325-345.

[6] Bhattacherjee, A., "An Empirical Analysis of the Antecedents of Electronic Commerce Service Continuance", Decision Support Systems, 32(2), 2001, pp. 201-214.

[7] Mithas, S., Ramasubbu, N., Krishnan, M.S., and Fornell, C., "Designing Web Sites for Customer Loyalty across Business Domains: A Multilevel Analysis", Journal of Management Information Systems, 23(3), 2006, pp. 97-127.

[8] Childers, T.L., Carr, C.L., Peck, J., and Carson, S., "Hedonic and Utilitarian Motivations for Online Retail Shopping Behavior", Journal of Retailing, 77(4), 2001, pp. 511-535.

[9] Diddi, A., and Larose, R., "Getting Hooked on News: Uses and Gratifications and the Formation of News Habits among College Students in an Internet Environment", Journal of Broadcasting \& Electronic Media, 50(2), 2006, pp. 193210 .

[10] Jaiswal, A.K., Niraj, R., and Venugopal, P., "ContextGeneral and Context-Specific Determinants of Online Satisfaction and Loyalty for Commerce and Content Sites", Journal of Interactive Marketing, 24(3), 2010, pp. 222-238.

[11] Hess, T., "What Is a Media Company? A Reconceptualization for the Online World", JMM: The International Journal on Media Management, 16(1), 2014, pp. 3-8.

[12] Lin, J.C.-C., and Lu, H., "Towards an Understanding of the Behavioural Intention to Use a Web Site", International Journal of Information Management, 20(3), 2000, pp. 197208.

[13] Carlson, J., and O'Cass, A., "Exploring the Relationships between E-Service Quality, Satisfaction, Attitudes and Behaviours in Content-Driven E-Service Web Sites", Journal of Services Marketing, 24(2), 2010, pp. 112-127.

[14] Gummerus, J., Liljander, V., Pura, M., and Van Riel, A., "Customer Loyalty to Content-Based Web Sites: The Case of an Online Health-Care Service", Journal of Services Marketing, 18(3), 2004, pp. 175-186.

[15] Eppler, M.J., Algesheimer, R., and Dimpfel, M., "Quality Criteria of Content-Driven Websites and Their Influence on Customer Satisfaction and Loyalty: An Empirical Test of an Information Quality Framework", Proceedings of the 8th International Conference on Information Quality (ICIQ), 2003, pp. 108-120. 
[16] Wang, Y.-S., "Assessing E-Commerce Systems Success: A Respecification and Validation of the DeLone and McLean Model of IS Success", Information Systems Journal, 18(5), 2008, pp. 529-557.

[17] Kim, C., Galliers, R.D., Shin, N., Ryoo, J.-H., and Kim, J., "Factors Influencing Internet Shopping Value and Customer Repurchase Intention", Electronic Commerce Research \& Applications, 11(4), 2012, pp. 374-387.

[18] DeLone, W.H., and McLean, E.R., "Information Systems Success: The Quest for the Dependent Variable", Information Systems Research, 3(1), 1992, pp. 60-95.

[19] Rai, A., Lang, S.S., and Welker, R.B., "Assessing the Validity of IS Success Models: An Empirical Test and Theoretical Analysis", Information Systems Research, 13(1), 2002, pp. 50-69.

[20] Seddon, P., and Kiew, M.-Y., "A Partial Test and Development of the DeLone and McLean Model of IS Success", Proceedings of the 15th International Conference on Information Systems, 1994, pp. 99-110.

[21] Seddon, P.B., "A Respecification and Extension of the DeLone and McLean Model of IS Success", Information Systems Research, 8(3), 1997, pp. 240-253.

[22] DeLone, W.H., and McLean, E.R., "The DeLone and McLean Model of Information Systems Success: A Ten-Year Update", Journal of Management Information Systems, 19(4), 2003, pp. 9-30.

[23] Molla, A., and Licker, P.S., "E-Commerce Systems Success: An Attempt to Extend and Respecify the DeLone and McLean Model of IS Success", Journal of Electronic Commerce Research, 2(4), 2001, pp. 131-141.

[24] McKinney, V., Yoon, K., and Zahedi, F.M., "The Measurement of Web-Customer Satisfaction: An Expectation and Disconfirmation Approach", Information Systems Research, 13(3), 2002, pp. 296-315.

[25] DeLone, W.H., and McLean, E.R., "Measuring ECommerce Success: Applying the DeLone \& McLean Information Systems Success Model", International Journal of Electronic Commerce, 9(1), 2004, pp. 31-47.

[26] Ahn, T., Ryu, S., and Han, I., "The Impact of the Online and Offline Features on the User Acceptance of Internet Shopping Malls", Electronic Commerce Research and Applications, 3(4), 2004, pp. 405-420.

[27] $\mathrm{Xu}$, J., Benbasat, I., and Cenfetelli, R.T., "Integrating Service Quality with System and Information Quality: An Empirical Test in the E-Service Context", MIS Quarterly, 37(3), 2013, pp. 777-794.
[28] Brown, I., and Jayakody, R., "B2C E-Commerce Success: A Test and Validation of a Revised Conceptual Model", Electronic Journal of Information Systems Evaluation, 12(2), 2009, pp. 129-147.

[29] Hellier, P.K., Geursen, G.M., Carr, R., A., and Rickard, J., A., "Customer Repurchase Intention: A General Structural Equation Model", European Journal of Marketing, 37(11/12), 2003, pp. 1762-1800.

[30] Katz, E., Blumler, J.G., and Gurevitch, M., "Uses and Gratifications Research", The Public Opinion Quarterly, 37(4), 1973, pp. 509-523.

[31] Katz, E., Haas, H., and Gurevitch, M., "On the Use of the Mass Media for Important Things", American Sociological Review, 38(2), 1973, pp. 164-181.

[32] Eighmey, J., and McCord, L., "Adding Value in the Information Age: Uses and Gratifications of Sites on the World Wide Web", Journal of Business Research, 41(3), 1998, pp. 187-194.

[33] Papacharissi, Z., and Rubin, A.M., "Predictors of Internet Use", Journal of Broadcasting \& Electronic Media, 44(2), 2000, pp. 175-196.

[34] Luo, M.M., and Remus, W., "Uses and Gratifications and Acceptance of Web-Based Information Services: An Integrated Model", Computers in Human Behavior, 38, 2014, pp. 281-295.

[35] Lin, J., "The Effects of Gratifications on Intention to Read Citizen Journalism News: The Mediating Effect of Attitude", Computers in Human Behavior, 36, 2014, pp. 129137.

[36] Zeithaml, V.A., "Consumer Perceptions of Price, Quality, and Value: A Means-End Model and Synthesis of Evidence", Journal of Marketing, 52(3), 1988, pp. 2-22.

[37] Babin, B.J., Darden, W.R., and Griffin, M., "Work and/or Fun: Measuring Hedonic and Utilitarian Shopping Value", Journal of Consumer Research, 20(4), 1994, pp. 644656.

[38] Wu, J.-H., Wang, S.-C., and Tsai, H.-H., "Falling in Love with Online Games: The Uses and Gratifications Perspective", Computers in Human Behavior, 26(6), 2010, pp. 1862-1871.

[39] Informationsgemeinschaft zur Feststellung der Verbreitung von Werbeträgern (IVW), OnlineNutzungsdaten. http://ausweisung.ivw-online.de/index.php? $\mathrm{i}=116 \& \mathrm{mz} \_s z m=201511$, accessed February 15, 2016.

[40] Sundar, S.S., "Multimedia Effects on Processing and Perception of Online News: A Study of Picture, Audio, and Video Downloads", Journalism \& Mass Communication Quarterly, 77(3), 2000, pp. 480-499. 
[41] Schaupp, L.C., Bélanger, F., and Fan, W., "Examining the Success of Websites Beyond E-Commerce: An Extension of the IS Success Model", Journal of Computer Information Systems, 49(4), 2009, pp. 42-52.

[42] Vincent, R.C., and Basil, M.D., "College Students' News Gratifications, Media Use, and Current Events Knowledge", Journal of Broadcasting \& Electronic Media, 41(3), 1997, pp. 380-392.

[43] Bhattacherjee, A., "Understanding Information Systems Continuance: An Expectation-Confirmation Model", MIS Quarterly, 25(3), 2001, pp. 351-370.

[44] Ringle, C.M., Wende, S., and Becker, J.-M., SmartPLS 3, SmartPLS GmbH, Boenningstedt, Germany, 2015.

[45] Cronbach, L.J., "Coefficient Alpha and the Internal Structure of Tests", Psychometrika, 16(3), 1951, pp. 297-334.

[46] Nunnally, J.C., and Bernstein, I.H., Psychometric Theory, 3rd edn., McGraw-Hill, New York, 1994.

[47] Hair, J.F., Ringle, C.M., and Sarstedt, M., "PLS-SEM: Indeed a Silver Bullet", Journal of Marketing Theory and Practice, 19(2), 2011, pp. 139-152.

[48] Fornell, C., and Larcker, D.F., "Evaluating Structural Equation Models with Unobservable Variables and Measurement Error", Journal of Marketing Research, 18(1), 1981, pp. 39-50.

[49] Henseler, J., Ringle, C.M., and Sinkovics, R.R., "The Use of Partial Least Squares Path Modeling in International Marketing", in (Sinkovics, R.R., and Ghauri, P.N., eds.): New Challenges to International Marketing, Emerald Group Publishing Limited, 2009, pp. 277-319.

[50] Cohen, J., Statistical Power Analysis for the Behavioral Sciences, 2nd edn., L. Erlbaum Associates, Hillsdale, NJ, 1988.

[51] Lopes, A.B., and Galletta, D.F., "Consumer Perceptions and Willingness to Pay for Intrinsically Motivated Online Content", Journal of Management Information Systems, 23(2), 2006, pp. 203-231.

\section{Appendix}

Items used in model analysis

Content quality (CONT), reflective adopted from Sundar [40]

For each word below, please indicate how well the word describes the news on [assigned website]:

1. Accurate

2. Believable

3. Comprehensive

4. Factual

5. Fair

6. Informative

7. Objective

8. Persuasive

System quality (SYST), formative adopted from Schaupp et al. [41]

1. The site is user friendly.

2. The site is easy to use.

3. The site is well organized.

Surveillance (SURV), reflective adopted from Vincent and Basil [42] I visit [assigned website] ...

1. so I can understand the world.

2. it shows what society is like nowadays.

3. it helps me judge what political leaders are really like.

4. so I can learn what is going on in the country and the world.

Entertainment (ENTE), reflective adopted from Vincent and Basil [42] I visit [assigned website] ...

1. because it's enjoyable.

2. because it's exciting.

3. because it's thrilling.

Satisfaction (SATI), reflective adopted from Bhattacherjee [43] How do you feel about your overall experience of using [assigned website]?

1. very dissatisfied / very satisfied

2. very displeased/very pleased

3. very frustrated / very contented

4. absolutely terrible / absolutely delighted

Intention to reuse (INTE), reflective adopted from Bhattacherjee [43]

1. I intend to continue using [assigned website] rather than discontinue its use.

2. My intentions are to continue using [assigned website] than use any alternative website.

3. If I could, I would like to discontinue my use of [assigned website]. (reversed) 